\title{
Relatos da Equipe de Saúde quanto às Práticas Educativas ao Vitimado no Trânsito durante a Hospitalização/Reabilitação num Hospital de Emergência'
}

\section{Health Care Team's Reports on Educational Practices for Road Traffic Victims during Hospitalization/Rehabilitation in an Emergency Hospital}

\author{
Luiza Jane Eyre de Souza Vieira \\ Enfermeira. Doutora em Enfermagem. Professora Titular do Curso \\ de Enfermagem e do Mestrado em Saúde Coletiva da Universidade \\ de Fortaleza (Unifor). \\ Endereço: Rua Ceres, 1157, Edson Queiroz, CEP 60834-180, Forta- \\ leza, CE, Brasil. \\ E-mail: janeeyreœunifor.br
}

\section{Edinilsa Ramos de Souza}

Psicóloga. Doutora em Ciências. Pesquisadora Titular do Demqs/ Claves/Ensp/Fiocruz. Endereço: Avenida Brasil, 4036, sala 700, Manguinhos, CEP 21040-361, Rio de Janeiro, RJ, Brasil.

E-mail: edinilsaळclaves.fiocruz.br

\section{Érika Porto Xavier}

Fisioterapeuta. Mestre em Educação em Saúde. Professora da Faculdade Integrada do Ceará (FIC).

Endereço: Rua Padre Januário Campos, 235, Cidade dos Funcionários, CEP 60822-840, Fortaleza, CE, Brasil.

E-mail: erikaporto®ibest.com.br

\section{Samira Valentim Gama Lira}

Enfermeira. Mestranda em Saúde Coletiva da Universidade de Fortaleza. Bolsista da CAPES.

Endereço: Rua Filgueiras Lima, 2, Damas, CEP 60425-800, Fortaleza, CE, Brasil.

E-mail: vagali®uol.com.br

\section{Renata Carneiro Ferreira}

Enfermeira. Mestranda em Saúde Coletiva da Universidade de Fortaleza.

Endereço: Rua Doutor Manoel Teófilo, 128, Parangaba, CEP 60710290, Fortaleza, CE, Brasil.

E-mail: renatada®ibest.com.br

I Financiamneto: Conselho Nacional de Desenvolvimento Científico

e Tecnológico - CNPq. Processo n. 50.4458/2004-3.

\section{Resumo}

O objetivo deste estudo foi analisar os relatos da equipe de saúde quanto às práticas educativas ao vitimado no trânsito durante a hospitalização/reabilitação, visando à minimização da instalação de sequelas traumato-ortopédicas. Este estudo foi realizado com 10 profissionais da equipe de saúde que trabalham em um hospital público de emergência em Fortaleza, Ceará, Brasil, em 2006. A entrevista semiestruturada foi a técnica utilizada para a coleta de dados, os quais foram submetidos à análise temática e discutidos à luz da Educação em Saúde e Promoção da Saúde. Para os participantes, a concepção sobre a prática educativa convergiu para o caráter preventivo, informacional e normativo; a equipe de saúde, apesar de não exercer o processo de assistência terapêutica integral e humanizada, alguns profissionais da equipe de saúde desenvolvem de forma tímida a prática educativa, desmitificando a Promoção da Saúde como foco da atenção primária. Desse modo, a reorientação da prática da equipe de saúde, com enfoque interdisciplinar à vítima de acidente de trânsito, pode ser um diferencial para minimizar a instalação de sequelas.

Palavras-chave: Acidentes de trânsito; Hospitalização; Reabilitação; Equipe de assistência ao paciente; Promoção da saúde. 


\section{Abstract}

The paper aims at analyzing the health care team's reports on educational practices to road traffic victims during the period of hospitalization and rehabilitation, trying to reduce traumatic orthopedic sequelae. The study was carried out with 10 professionals from the health care team who work in a public emergency hospital in the city of Fortaleza, State of Ceará, Brazil, in 2006. The semi-structured interview was the technique for collecting data and these were submitted to thematic analysis and then discussed in the light of Health Education and Health Promotion. To the participants, the conception of educational practice converged to a preventive, informational, and normative approach; although the health care team did not accomplish with integrality and humanization the therapeutic support to individuals, they developed a timid educational practice, which demystifies Health Promotion as the focus of primary care. Thus, the reorientation of the health care team's practice, based on an interdisciplinary approach to road traffic victims, can help minimize the incidence of sequelae.

Keywords: Traffic Accidents; Hospitalization; Rehabilitation; Health Care Team; Health Promotion.

\section{Introdução}

Algumas publicações temáticas sobre acidentes e violências mostram que o acidente de trânsito provoca impacto na saúde física, emocional e social das pessoas e famílias, além de sérios prejuízos na economia do país. Essa percepção está evidenciada nos dados de morbimortalidade, na necessidade de reestruturação da malha viária, na ineficiência de reprimir as infrações e, principalmente, na efetividade de programas educativos que sensibilizem a população quanto à prevenção dos fatores de riscos (WHO, 2004; Brasil, 2005; OMS, 2006).

A magnitude alcançada pelos acidentes de trânsito torna-se importante para a saúde coletiva, pois, além da sua frequência, esses eventos atingem uma população jovem e são considerados teoricamente previsíveis e passíveis de prevenção (Brasil, 2002a; Barros e col., 2003; Salter e Stallard, 2004).

A pessoa vitimada pelo trânsito, como preconiza a Política Nacional de Atenção às Urgências (Brasil, 2003), deve ser assistida, inicialmente, pelo atendimento pré-hospitalar e, em seguida, encaminhada aos serviços de emergência para que possa manter e restabelecer sua funcionalidade e integridade física. Diante disso, ressalta-se a importância da reabilitação, pois é preciso restaurar ou desenvolver novamente habilidades funcionais que ficaram comprometidas como consequência do acidente.

Tido como uma das formas de violência, o acidente de trânsito contribui para sobrecarregar os atendimentos dos serviços de emergência. Deslandes (1999) assinala que em nenhum outro serviço de saúde a violência adquire tamanha visibilidade como na emergência, considerada porta de entrada do serviço público de saúde; são onerosos e de grande complexidade os investimentos nesse tipo de atenção.

Evidenciando-se a magnitude desse problema, em São Paulo, no ano de 2000 , foram registradas 29.803 internações referentes a acidentes de trânsito, com tempo médio de 5,7 dias e gasto de R\$ 132,18 por dia de internação (Mello-Jorge e Koizumi, 2004). A literatura retrata que crianças e idosos são grupos mais vulneráveis a esse tipo de acidente, contribuindo para o aumento do tempo de internação e dos custos para o sistema de saúde (Schvartsman e col., 2005; Brasil, 2005). 
O custo despendido com a hospitalização/reabilitação também é um fator que deve ser discutido, pois exige recurso material e humano qualificado. Faz-se, todavia, necessária uma reorientação na formação dos profissionais da saúde para que eles possam ser sujeitos do processo educativo no intuito de responder às novas demandas impostas pelo vitimado no trânsito (Brasil, 2004a).

A díade hospitalização/reabilitação concretiza-se na medida em que os profissionais que estruturam e operacionalizam o cuidado ao paciente politraumatizado transcendem os aspectos biomédicos e sinalizam uma prática orientada para o modelo de atenção à saúde, que tenta sua consolidação. Esse modelo preconiza a implementação da cadeia do cuidado complexo e a visão da clínica ampliada no alcance da cura ou no convívio com algum tipo de limitação (Brasil, 2004b).

Sendo assim, para se desfrutar de saúde, é preciso dispor-se de recursos sociais e pessoais, bem como de capacidade física para agir. Essa asserção se insere nas diretrizes da Política da Promoção da Saúde, que instrumentaliza as pessoas para o desempenho de uma ação integrada e multidisciplinar, incluindo as dimensões subjetivas, social, política, econômica e cultural, da experiência humana e coloca a serviço da saúde os saberes e as ações produzidos nos diferentes campos do conhecimento e das múltiplas atividades (Brasil, 2002b).

Nessa perspectiva, o enfoque problematizador da educação que valoriza e respeita a autonomia e individualidade cultural e científica oferece os subsídios necessários para o exercício interdisciplinar da equipe de saúde no aprimoramento de sua assistência, ao compartilhar conhecimentos, habilidades e atitudes, com o intuito de minimizar a instalação de sequelas traumato-ortopédicas decorrentes dos acidentes de trânsito (Saupe e col., 2005).

A participação da equipe de saúde no processo de saúde-doença do acidentado no trânsito, entretanto, é complexa porque precisa oferecer apoio a essa vítima, lidar com sentimentos de incerteza, medo e insegurança diante de sua nova condição, ou seja, como portador de limitações traumato-ortopédicas que poderá ou não retornar às suas atividades em detrimento dos seus projetos de vida.

Nesse contexto, o ambiente hospitalar necessita buscar modelos de atenção à saúde que extrapolem a assistência médico-curativa, desenvolvendo bases formadoras do autocuidado do acidentado no trânsito e, consequentemente, gestão da própria saúde, priorizando sua atuação nos determinantes da doença e não apenas em sua ausência (Sícoli e Nascimento, 2003).

Nesse sentido, a Política Nacional de Redução da Morbimortalidade por Acidentes e Violências (Brasil, 2002a) considera que os profissionais e gestores devem atender aos três níveis de atenção à saúde. Desse modo, a reabilitação é também considerada essencial para minimizar as incapacidades oriundas dos acidentes de trânsito, pois os serviços de reabilitação ainda vêm proporcionando cuidados precários aos vitimados no trânsito (Deslandes e col., 2006).

Assim sendo, este estudo pressupõe que durante a hospitalização-reabilitação é possível inserir a Educação em Saúde e contribuir para minimizar a instalação de sequelas traumato-ortopédicas à vítima de acidente de trânsito e que o paciente é receptivo a essa prática, desde que articulada e interdisciplinar. Nessa linha de raciocínio, o artigo analisa os relatos da equipe de saúde quanto às práticas educativas ao vitimado no trânsito durante a hospitalização/reabilitação.

\section{Metodologia}

Realizou-se um estudo exploratório de cunho qualitativo que, segundo Minayo (2004), possibilita que o pesquisador se aprofunde no mundo subjetivo das ações humanas e nos aspectos não perceptíveis ou captados por medidas e equações estatísticas. Esse método de investigação lhe permite aproximar-se de uma gama de informações (explícitas ou encobertas na vida cotidiana das pessoas), pois as ações humanas estão baseadas em significados sociais e incorporadas por elas: intenções, motivos, atitudes e crenças (Hammersley e Atkinson, 1994).

A pesquisa foi realizada em um hospital público de referência no atendimento em urgência e emergência na cidade de Fortaleza, Ceará, Brasil, durante os meses de setembro a outubro de 2006. Vale ressaltar que no ano de realização deste estudo, esse hospital atendeu 14.699 vítimas de acidentes de 
trânsito, provenientes da capital e de outras cidades do estado (IJF, 2006).

Como participantes do estudo, foram selecionados distintos profissionais da equipe de saúde. Foram critérios de inclusão: o profissional possuir escala fixa na instituição ou estar cursando residência em Traumatologia (médico), trabalhar nas unidades de Traumatologia e aceitar participar do estudo de forma espontânea. Foram excluídos profissionais recém-contratados pela instituição e os que em sua dinâmica profissional não estabelecem vínculos com o acidentado no trânsito, além dos que não aceitassem participar da pesquisa.

Realizou-se uma entrevista semiestruturada com dez profissionais, dos quais seis eram do sexo feminino, na faixa etária de 24 a 59 anos, com idade média 42,4 anos e pertencentes às categorias profissionais: Fisioterapia (3), Medicina (3), Serviço Social (2) e Enfermagem (2). O tempo de formação e de serviço na Instituição variou de 1 a 33 anos, com média, respectivamente, de 14 anos. Seis profissionais trabalhavam exclusivamente no hospital em estudo, enquanto os demais também desempenham atividades em outras instituições.

As entrevistas versaram sobre práticas educativas - descrição da concepção sobre orientações educativas; instalação de sequelas - descrição das orientações educativas que a equipe de saúde fornece aos pacientes vítimas de acidentes de trânsito para evitar a instalação de sequelas; hospitalização/ reabilitação - percepção da equipe de saúde sobre a hospitalização/reabilitação do acidentado no trânsito portador de trauma musculoesquelético; e equipe de saúde - o trabalho do profissional perante a equipe de saúde.

Os questionamentos listados na entrevista foram desenvolvidos em decorrência da experiência profissional das autoras na temática de urgência e emergência. Em seguida, apenas uma das autoras abordou os profissionais de saúde durante o horário de expediente para tecer explicações sobre a pesquisa, e, posteriormente, num lugar reservado, realizou um encontro em diferentes dias, com cada profissional, com duração média de cinquenta minutos.

As entrevistas foram gravadas e transcritas na íntegra, complementadas com observações e anotações em um diário de campo. As observações acompanharam todas as etapas do estudo e focalizaram a dinâmica percebida no atendimento do profissional e nas relações entre os profissionais da equipe de saúde com as pessoas hospitalizadas. Teve como intuito confrontar a prática profissional com o discurso dos participantes e analisá-los a partir dos construtos da educação em saúde, integralidade, visão humanística e promoção da saúde.

As anotações realizadas por uma das autoras subsumiram as reflexões sobre a cultura organizacional e o processo de trabalho da equipe de saúde desta unidade de traumatologia, para identificar e analisar se as condições de trabalho e a rotina hospitalar favoreciam a efetivação de uma prática promotora de saúde, no nível terciário, visando minimizar a instalação de sequelas.

Os relatos dos participantes foram submetidos à análise de Bardin (2004), partindo-se de categorias predefinidas - orientações educativas, instalação de sequelas, hospitalização/reabilitação e equipe de saúde, que a partir de leitura flutuante do material coletado (entrevista e diário de campo), a organização e reflexão sobre o tema, respaldado nos conceitos de Promoção da Saúde (Brasil, 2002a) configuraram as seguintes categorias empíricas (1) práticas educativas; (2) processo de hospitalização-reabilitação; e (3) desempenho da equipe de saúde.

0 estudo obedeceu aos preceitos éticos da Resolução 196/96 (Brasil, 1996). Todos os participantes foram informados sobre os objetivos da pesquisa, que não incorriam em nenhum tipo de risco e poderiam se desligar em qualquer uma de suas fases. Após aceitarem o convite, todos assinaram o Termo de Consentimento Livre e Esclarecido. O projeto foi aprovado pelo Comitê de Ética e Pesquisa da Instituição locus do estudo, sob nº. 04537/o6.

\section{Apresentação e Discussão dos Resultados}

\section{Práticas educativas}

As concepções dos sujeitos do estudo sobre as práticas educativas convergiram para o caráter de orientação preventiva no contexto da hospitalização/reabilitação, assim como enfatizaram conotações de informações, esclarecimentos e normas. 
É uma maneira de você orientar as pessoas, o paciente sobre as formas de prevenção (Fisioterapeuta 1). Orientação educativa é aquela informação que uma pessoa capacitada, habilitada em dar, passa essa informação para o estudante ou mesmo profissionais que queiram se reciclar (Fisioterapeuta 2).

De acordo com Barroso e colaboradores (2003), a Educação em Saúde não se restringe apenas à prevenção de doenças e agravos, constitui um processo de qualificação do indivíduo, norteado por valores humanísticos, para o exercício da cidadania e, portanto, em promoção da qualidade de vida.

As formas de prevenção de agravos à saúde são efetivadas por intermédio de uma ação interdisciplinar e intersetorial (transporte, engenharia de tráfego, segurança, educação e saúde) que vise à redução no número de acidentes de trânsito, enfocando fatores de risco, como alcoolismo, alta velocidade, sonolência e cansaço, dentre outros, e o reforço da noção de perigo ante as infrações cometidas pelos usuários do trânsito (motoristas e pedestres).

A percepção das autoras foi confirmada na fala dos entrevistados.

[...] eu entendo que deve ser prevenção pras pessoas pra evitar determinados acidentes, como por exemplo, a questão do alcoolismo, da alta velocidade misturando essas duas coisas, por conta disso que acontece o acidente (Assistente social 1).

No discurso oficial e nas concepções dos estudiosos dessa temática, preconiza-se que a ação conjunta dos profissionais de saúde priorize as dimensões comportamentais e culturais dos envolvidos na busca de soluções para a problemática dos acidentes de trânsito, sugerindo a implementação de políticas públicas que valorizem programas de educação para o trânsito (Brasil, 2005; Queiroz e Oliveira, 2003). É importante frisar, no entanto, que outros fatores determinantes também estão presentes, como a má conservação das estradas e da sinalização do trânsito, que dependem das iniciativas dos órgãos gestores e não do comportamento de seus usuários.

A equipe interdisciplinar enfatiza o trabalho educativo nos diversos níveis de atenção à saúde, destacando a promoção e a prevenção, o que é corro- borado pelo discurso do sujeito: "as orientações educativas podem ser preventivas: prevenção primária, secundária e terciária” (Médico 2), bem como pelas diretrizes da Política Nacional de Promoção da Saúde (Brasil, 2002b), que preconiza estimular as ações intersetoriais, buscando parcerias que propiciem o desenvolvimento integral das ações de Promoção da Saúde, e fortalecer a participação social, como ação fundamental na consecução de resultados de Promoção da Saúde.

Legitimando essa compreensão, Ceccim e Feuerwerker (2004) retratam que uma prática educativa que atenda às necessidades dos diversos níveis de atenção à saúde sustenta-se em quatro pilares: ensino, gestão, atenção e controle social.

As orientações educativas possuem como fundamento os quatro pilares mencionados, que juntos fortalecem a capacidade comunicativa e de potencial multiplicador de "informações fidedignas e recentes [...] cientificamente pra você repassar" (Fisioterapeuta 3). Trata-se de um processo que elucida e explicita negligências cometidas no trânsito, no intuito de favorecer mudanças nos comportamentos das pessoas, entendidos pelos participantes como "consequências de atos, atitudes [...] vão dar como consequência de algo" (Médico 2). Para isso, o apoio do governo que, por intermédio de programas educativos e dos diversos mecanismos de regulação, instrui os profissionais e melhora a vida da sociedade.

Desse modo, o ensino centrado em uma formação cidadã e baseado em evidências, uma gestão que objetiva melhorar os indicadores sociossanitários, uma atenção à saúde individual e coletiva com coparticipação responsável dos sujeitos e um controle social efetivo que cobre melhorias no caos que se instalou no trânsito oportunizam o atendimento das demandas sociais e de saúde da população brasileira.

O Programa de Redução de Morbimortalidade por Acidentes de Trânsito (Brasil, 200o) visa sensibilizar os gestores quanto à sua responsabilidade perante o significativo impacto econômico e social dessa problemática da saúde. É exigido esforço considerável de integração, ao envolver órgãos federais, estaduais e municipais ligados à questão do trânsito, concentrando esforços em um plano que envolva usuários e instituições responsáveis, fornecendo 
insumos e orientações às pessoas, desde a escola primária até a vida adulta, sem interrupção (Queiroz e Oliveira, 2002).

Quanto às práticas educativas referidas pela equipe de saúde investigada, foi identificado o fato de que, além da reabilitação funcional do segmento acometido, alcançado por meio da aprendizagem de exercícios, esses profissionais se comprometem com a saúde emocional. Para a resolubilidade das sequelas, a reabilitação ultrapassa os aspectos meramente físicos do cuidado. Para isso, as práticas educativas precisam atentar também para os aspectos emocionais, no sentido de motivar o paciente em busca da reabilitação, como mencionado por um dos participantes: "nós sempre orientamos uma reabilitação funcional do segmento acometido e a reabilitação psicológica se necessário. 0 grau de motivação" (Médico 3).

Deslandes (2004), em análise do discurso oficial sobre a humanização da assistência hospitalar, expressa que se faz necessária uma visão humanística do profissional de saúde no sentido de delinear uma práxis assistencial mais efetiva, pautada na alteridade e no diálogo.

Na humanização do tratamento, o profissional perpassa pela assistência ao paciente lesionado no percurso de sua terapêutica até a sua reinserção social. Esse entendimento é claro para o profissional da equipe de saúde, ao referir que "operar é o primeiro ponto até aquele objetivo final que seria o retorno às atividades anteriores ao acidente" (Médico 1), enfatizando, desse modo, o regresso do vitimado no trânsito à vida cotidiana.

Visando ao máximo de independência do paciente, diante da execução das atividades da vida diária, a equipe de saúde, valorizando a biomecânica articular, minimiza as incapacidades funcionais e, cônscio de sua prática, verbaliza: "ele vai sentir dores no joelho devido ao medo de movimentar e vai apresentando bloqueio, vai apresentando edema. Se ele movimenta esta articulação ele já vai melhorar no dia a dia" (Fisioterapeuta 1).

Nesse sentido, é importante nortear a prática de acordo com protocolos de reabilitação dirigidos aos vitimados pelo trânsito, como descritos nos estudos de Saad e Zambon (2001); Bosco e colaboradores (2004); Beaupre e colaboradores (2005) e Macleod e colaboradores (2005).

A utilização de protocolos possibilita à equipe de saúde avaliar o processo de reabilitação, por meio de acompanhamento mensal, de acordo com o tipo de lesão e de orientações fornecidas. Esse pensamento está congruente com a prática exercida por essa equipe: "nós avaliamos em relação ao sistema musculoesquelético, a gente observa [...] a sua sequela que está sendo resolvida" (Médico 3).

A literatura retrata que, ao restaurar ou desenvolver habilidades na participação de atividades funcionais decorrentes da disfunção física, mental ou social, se fortalece o enfoque educativo na reabilitação, contrariando a cultura da "medicalização", que impõe um declínio da capacidade de enfrentamento autônomo da maior parte dos adoecimentos e dores cotidianas (Moraes e col., 2003; Tesser, 2006). Esse enfoque no contexto da hospitalização/reabilitação minimiza a instalação de sequelas e contribui para acelerar o retorno dos pacientes à vida social.

Relatos demonstraram que alguns pacientes impuseram objeções ao processo educativo realizado pela equipe interdisciplinar. Segundo uma profissional, os pacientes "não acreditam, às vezes, no que a gente diz. Com o médico já é diferente, eles sempre questionam: mas o médico disse que era assim" (Enfermeira 2).

Saupe e colaboradores (2005) ressaltam que a interdisciplinaridade ainda se mostra como um desafio na solidificação da prática desses profissionais, apesar de ser um dos conceitos nucleares para a consolidação das políticas públicas na área da saúde.

No discurso dos profissionais de saúde, as práticas educativas visam à prevenção das sequelas traumato-ortopédicas, porém, a partir das observações do campo, identificou-se que a orientação fornecida pela equipe é fragmentada e dificulta a inserção dos princípios humanísticos e integrais como preconizados pelas diretrizes da Educação em Saúde e Promoção da Saúde.

\section{A hospitalização-reabilitação e o desempenho da equipe de saúde}

Outro problema é o hiato no exercício da prática interdisciplinar, decorrente da fragmentação da equipe de saúde, aliada à grande demanda do usuário em 
detrimento do número reduzido de profissionais, repercutindo nas condições de trabalho. Essa assertiva é percebida na seguinte fala: "É muito diferente do que eu vi aí fora, se trabalha com paciente, se trabalha com uma equipe [...] esse paciente faz parte de uma equipe, você faz sua parte, eu faço a minha, fulano de tal faz a sua" (Fisioterapeuta 2).

Hoga (2004) esclarece que as dificuldades decorrentes da hospitalização prolongada e uma prática profissional fragmentada tornam o atendimento em saúde dependente da dinâmica administrativa da instituição, do gerenciamento dos diversos serviços e das possibilidades oferecidas para efetivar os princípios de humanização. Essa necessidade da assistência em saúde demanda uma participação interdisciplinar complexa, pois nenhuma categoria contempla, por si só, a totalidade humana na vivência do processo saúde-doença.

Nessa linha de raciocínio, amplia-se o atendimento da equipe de saúde ao paciente que fica a par de seus direitos. Neste estudo, o Serviço Social é peça importante na informação e acompanhamento dos benefícios decorrentes do Seguro de Danos Pessoais Causados por Veículos Automotores de Vias Terrestres (DPVAT). Segundo uma profissional: “[...] às vezes o paciente recebe dentro do hospital por estar muito tempo no hospital" (Assistente social 2).

Desse modo, Deslandes (2002) coloca que a comunicação entre profissional de saúde e paciente está centrada na escuta acolhedora, no diálogo e na partilha do conhecimento científico, ocasionando um feedback positivo entre ambos.

É imprescindível que a equipe interdisciplinar evidencie seu papel ativo ante a redução das sequelas, buscando compreender a percepção sobre a hospitalização/reabilitação. "Acho que são coisas que andam bem conjuntas, você não pode separar uma coisa da outra" (Assistente social 2). Ao analisar a Política de Humanização (Brasil, 2004a), Deslandes (2004) pontua que a equipe de saúde se mostra efetiva quando a assistência se alicerça sob uma perspectiva humanística que valoriza a qualidade do cuidado do ponto de vista técnico, associada ao reconhecimento dos direitos do paciente, de sua subjetividade e referências culturais.

Nesse contexto, discutir de forma participativa a relevância do autocuidado com o intuito de prevenir deficiências ou comprometimentos além dos existentes é um dos eixos da atenção à saúde. O profissional fisioterapeuta verbaliza a importância de "mobilizações no leito para tentar evitar as escaras do paciente, sentá-lo na posição confortável tentando evitar prejudicar os tecidos que estão comprometidos" (Fisioterapeuta 1).

A literatura confirma que programas de reabilitação interdisciplinar se mostram como alternativas eficazes para evitar complicações decorrentes da imobilização no leito, auxiliando na reaquisição da mobilidade funcional (Blanes, 2004; Latham e col., 2006).

A precocidade da reabilitação no acompanhamento ao acidentado requer uma atuação contínua e, muitas vezes, em longo prazo, como referida por um dos participantes: "[...] a reabilitação psicológica, social do paciente, e também a reabilitação dos outros sistemas fisiológicos que não musculoesquelético ajudam recuperar mais rápido esses pacientes" (Médico 3).

Nesse sentido, a agilidade em se iniciar um processo terapêutico com visão da integralidade favorece, nas vítimas de acidente de trânsito, a possibilidade do retorno ou a adaptação mais imediata à nova realidade de suas atividades da vida diária.

Essa visão integral vai o encontro do que preconiza o conceito de Clínica Ampliada, do Ministério da Saúde (Brasil, 2004C), ao propor que o profissional de saúde desenvolva a capacidade de prestar assistência às pessoas. Acrescenta que essa capacidade não deva ser usada apenas no combate às doenças, mas também no sentido de oferecer-lhes a possibilidade de transformação, de modo que a doença, mesmo sendo um limite, não as impeça de viver outras facetas da vida.

0 processo de reabilitação inicia-se no setor da emergência hospitalar com a chegada e a admissão do acidentado: "a hospitalização eu acho que tem que entrar por um sistema de urgência e emergência que funcione adequadamente" (Médico 3). Esse processo atende ao politraumatizado com protocolos padronizados e ocorre no menor tempo possível. É imprescindível que sejam "[...] avaliadas as lesões mais graves que oferecem risco à vida e depois as lesões musculoesqueléticas que causam maior comorbidades" (Médico 1). 
Vale acrescentar que é importante o preenchimento da ficha de notificação de acidentes e violências para delinear o perfil dessas ocorrências e contribuir com o monitoramento da Política Nacional de Redução da Morbimortalidade por Acidentes e Violências, como relatam Assis e colaboradores (2007).

Além do preenchimento da ficha de notificação, é essencial que um hospital de emergência disponha de um núcleo interdisciplinar direcionado ao atendimento da vítima de acidentes e violências, para nortear o cuidado prestado pela equipe de saúde a esses cidadãos. De acordo com Sarti (2005), isso já é vivenciado em um hospital municipal de São Paulo.

Corroborando a assertiva anterior, Deslandes (2002) afirma que uma dinâmica de socorro e atendimento ágil e eficaz às vítimas de acidente de trânsito demanda uma reorganização das equipes dos serviços de emergência para garantir um atendimento de maior complexidade, a fim de dar continuidade ao atendimento aos que sofreram sequelas e que precisarão de apoio para a reabilitação.

Portanto, o pronto-atendimento enseja a equipe de saúde à ação conjunta, por terem papel fundamental na reabilitação, "médico tá preocupado [...] em salvar a vida de imediato [...], a gente tá pra ver qual a postura [...], que tipo de lesão" (Fisioterapeuta 2). Entretanto, a literatura preconiza que o atendimento centrado na manutenção da vida, na reaquisição da capacidade funcional e no acolhimento seja uma prática cotidiana (Bastos e col., 2005).

A comunicação efetiva entre a equipe de saúde propicia o fornecimento de subsídios ao paciente, que precisa de uma hospitalização prolongada. Na fala do profissional, "o que pode acontecer é uma simbiose entre eu e você" (Fisioterapeuta 2), identificando-se nessa interação uma prática interdisciplinar. É nesse sentido que Saupe e colaboradores (2005) ressaltam a importância do trabalho interdisciplinar que, para eles, se estabelece de forma natural e solidária, ultrapassando a arrogância pessoal, o exercício do poder e a centralização de um profissional sobre o outro.

Portanto, visando a uma prática interdisciplinar mediante uma ação conjunta entre a equipe de saúde e a educação continuada surge como possibilidade promissora para o desenvolvimento de uma maior competência por parte da equipe de saúde, articulando responsabilidade, liberdade e compromisso em relação às práticas de saúde (L’Abbate, 1999).

Ante o processo de reabilitação, a equipe de saúde proporciona melhor assistência ao paciente politraumatizado, dialogando de maneira clara e precisa. A fala de um dos sujeitos retrata que nem todos os profissionais estão aptos a desenvolver uma assistência de qualidade "[...] mas só que eles não têm conhecimento" (Enfermeira 1). Nesse sentido, a Política de Educação Permanente visa à reorganização dos serviços e das práticas de saúde por intermédio da qualificação dos profissionais, sem deixar de visualizar as competências existentes (Brasil, 2004c).

A qualificação dos profissionais na prestação da assistência, aliada ao entrosamento da equipe, repercute no desempenho da equipe de saúde, ao compartilhar o conhecimento mais específico das distintas áreas para saber o que se passa com o paciente, "[...] acho interessante você estar sabendo o que está passando com o paciente dentro das outras disciplinas" (Enfermeira 2). Uma equipe com filosofia interdisciplinar implica na não invasão da área do outro, mas na soma dos saberes em prol do cuidado humano, "[...], mas você chegando, está ocupada, dando pra eu fazer, cada um teria que ter um pouquinho do outro, o paciente agradeceria" (Enfermeira 2).

Apesar de a equipe de saúde estar constituída por distintas categorias profissionais, a assistência por ela prestada ainda é fragmentada, "não tem nada de ninguém com ninguém, você chega aqui faz o seu trabalho", como citado pela Fisioterapeuta 2.

Backes (2005) relata que a instituição hospitalar constitui um ambiente em que o trabalhador libera suas potencialidades e compartilha uma meta coletiva, para atender à nova tendência caracterizada pela integralidade, contrapondo-se à fragmentação de especialidades e à dissociação de conhecimentos, como defendem Ceccim e Feuerwerker (2004).

Esta realidade ainda não se visualiza nas instituições hospitalares. Gomes e colaboradores (2008) detectaram que o hospital público no nordeste brasileiro se configura como uma instituição que reproduz uma prisão com suas normas restritivas e 
regras rigorosas enraizadas na violência estrutural. Todavia, a transformação do paradigma vigente em outro, humanístico e inclusivo, revela-se desafiador pela árdua tarefa de erradicar determinantes sociais, de tão ampla magnitude, e minimizar seus efeitos na vida dos sujeitos pacientes.

Desse modo, no tocante às ações que visam à reversão das limitações traumato-ortopédicas de pessoas vitimadas pelo trânsito, os profissionais muitas vezes se veem obrigados a priorizar o atendimento: "[...] você tem que selecionar o mais grave do menos grave" (Fisioterapeuta 3 ).

As observações de uma das autoras em relação à dinâmica do serviço permitiram inferir que os membros da equipe de saúde exercem, de forma tênue, as práticas educativas, porém se faz necessária maior interação entre os profissionais para que eles respondam às demandas física, social e emocional do vitimado no trânsito.

\section{Considerações Finais}

A educação permanente, com base nos princípios da integralidade da atenção e da interdisciplinaridade, preconizada pelas políticas públicas do setor saúde e própria ao enfoque de temas complexos, como o dos acidentes de trânsito, fará a diferença nos atendimentos de emergências.

As práticas educativas convergiram para o caráter preventivo, informacional e normativo. Os conceitos de Educação em Saúde e Promoção da Saúde que emergiram da prática da equipe de saúde em estudo aproximam-se dos princípios da interdisciplinaridade, visão humanística e integralidade. Essa prática pode avançar na assistência aos vitimados pelo trânsito, se acrescentar a abordagem socioeducativa, ou seja, chamar atenção desse acidentado para a sua corresponsabilidade na gênese desses acidentes de trânsito.

Foram encontradas contradições nos discursos dos membros da equipe de saúde, pois, apesar de não exercerem o processo de assistência terapêutica, integral e humanizada ao paciente em sua totalidade, desenvolvem de forma tímida a prática educativa, desmistificando que a promoção da saúde se dá apenas no campo de atuação da atenção primária, mostrando que esta acompanha a cadeia complexa do cuidado ao cidadão.

Portanto, a reorientação da prática da equipe de saúde para um enfoque interdisciplinar, a fim de oferecer suporte no que se refere ao desempenho das atividades laborais, sociais e culturais do vitimado no trânsito, perpassa pela reorientação da formação acadêmica.

\section{Referências}

ASSIS, S. G.; DESLANDES, S. F.; MINAYO, M. C. S. Prevenção, monitoramento, capacitação e pesquisa. In: MINAYO, M. C. S.; DESLANDES, S. F. (Org.). Análise diagnóstica da política nacional de saúde para redução de acidentes e violências. Rio de Janeiro: Fiocruz, 2007. p. 193-218.

BACKES, D. S. O processo de humanização do ambiente hospitalar centrado no trabalhador. Revista da Escola de Enfermagem da USP, São Paulo, v. 4O, n. 2, p. 221-227, 2005.

BARDIN, L. Análise de conteúdo. 3. ed. Lisboa: Ed. 70, 2004.

BARROS, A. J. D. et al. Acidentes de trânsito com vítimas: sub-registro, caracterização e letalidade. Cadernos de Saúde Pública, Rio de Janeiro, v. 19, n. 4, p. 979-986, 2003.

BARROSO, G. T.; VIEIRA, N. F. C.; VARELA, Z. M. de V. Educação em saúde no contexto da promoção humana. Fortaleza: Ed. Demócrito Rocha, 2003.

BASTOS, Y. G. L.; ANDRADE, S. M.; SOARES, D. A. Características dos acidentes de trânsito e das vítimas atendidas em serviço pré-hospitalar em cidade do Sul do Brasil, 1977/200o. Cadernos de Saúde Pública, Rio de Janeiro, v. 21, n. 3, p. 815$822,2005$.

BEAUPRE, L. A. et al. Does standardized rehabilitation and discharge planning improve function recovery in elderly patients with hip fracture? Archives of Physical Medicine and Rehabilitation, New York, v. 86, n. 12, p. 2231-2239, 2005 .

BLANES, L. Avaliação clínica e epidemiológica das úlceras por pressão em pacientes internados no Hospital São Paulo. Revista da Associação Médica Brasileira, São Paulo, v. 5o, n. 2, p. 182-187, 2004. 
BOSCO, R. et al. O efeito de um programa de exercício físico aeróbio combinado com exercícios de resistência muscular localizada na melhora da circulação sistêmica e local: um estudo de caso. Revista Brasileira de Medicina do Esporte, São Paulo, v. 10, n. 1, p. 56-62, 2004.

BRASIL. Ministério da Saúde. Resolução 196/96. Diretrizes e normas técnicas regulamentadoras de pesquisa envolvendo seres humanos. Brasília, DF, 1996.

BRASIL. Ministério da Saúde. Resolução 196. Programa de Redução da Morbimortalidade por Acidentes de Trânsito. Brasília, DF, 2000.

BRASIL. Ministério da Saúde. Política Nacional para Redução de Morbimortalidade por Acidentes e Violências. Brasília, DF, 200za.

BRASIL. Ministério da Saúde. Política Nacional de Promoção da Saúde. Brasília, DF, 2002b.

BRASIL. Ministério da Saúde. Política Nacional de Atenção às Urgências. Brasília, DF, 2003.

BRASIL. Ministério da Saúde. Política Nacional de Humanização. Brasília, DF, 2004a.

BRASIL. Ministério da Saúde. Clínica ampliada. Brasília, DF, 2004b.

BRASIL. Ministério da Saúde. Política Nacional de Educação Permanente. Brasília, DF, 2004C.

BRASIL. Ministério da Saúde. Impacto da violência na saúde dos brasileiros. Brasília, DF, 2005.

CECCIM, R. B.; FEUERWERKER, L. C. M. O quadrilátero da formação para a área da saúde: ensino, gestão, atenção e controle social. Interface: Comunicação, Saúde, Educação, São Paulo, v. 14, n. 1, p. 41-65, 2004.

DESLANDES, S. F. $O$ atendimento às vítimas de violência na emergência: "prevenção numa hora dessas?”. Ciência $\varepsilon$ Saúde Coletiva, Rio de Janeiro, v. 4, n. 1, p. 81-94, 1999.

DESLANDES, S. F. Frágeis deuses: profissionais da emergência entre os danos da violência e a recriação da vida. Rio de Janeiro: Fiocruz, 2002.
DESLANDES, S. F. A análise do discurso oficial sobre a humanização da assistência hospitalar, São Paulo, Brasil. Ciência e Saúde Coletiva, Rio de Janeiro, v. 9, n. 1, p. 7-14, 2004.

DESLANDES, S. F. et al. Diagnostic characterization of services providing care to victims of accidents and violence in five Brazilian state capitals. Ciência e Saúde Coletiva, Rio de Janeiro, v. 11, n. 2, p. 385-396, 2006.

GOMES, A. M. A.; NATIONS, M. K.; LUZ, M. T. Pisada como pano de chão: experiência de violência hospitalar no nordeste brasileiro. Saúde e Sociedade, São Paulo, v. 17, n. 1, p. 61-72, 2008.

HAMMERSLEY, M.; ATKINSON, P. Etnografía: métodos de investigación. Buenos Aires: Paidó, 1994 .

HOGA, L. A. K. A dimensão subjetiva do profissional na humanização da assistência à saúde: uma reflexão. Revista da Escola de Enfermagem da USP, São Paulo, v. 38, n. 1, p. 13-20, 2004.

IJF- INSTITUTO DOUTOR JOSÉ FROTA. Estatísticas de atendimentos por acidentes de trânsito - 2006. Fortaleza, 2006.

L’ABBATE, S. Educação e serviços de saúde: avaliando a capacitação dos profissionais. Cadernos de Saúde Pública, Rio de Janeiro, v. 15, n. 2, p. 15-27, 1999.

LATHAM, N. K. et al. Pattern of function change during rehabilitation of patients with hip fracture. Archives of Physical Medicine and Rehabilitation, New York, v. 87, n. 1, p. 111-116, 2006.

MACLEOD, M. et al. To what extent are carers involved in the car and rehabilitation of patients with hip fracture? Disability and rehabilitation: an international, multidisciplinary journal, Ipswich, v. 27, n. 18/19, p. 1117-1122, 2005.

MELLO-JORGE, M. H. P.; KOIZUMI, M. S. Gastos governamentais do SUS com internações hospitalares por causas externas: análise do Estado de São Paulo, 200o. Revista Brasileira de Epidemiologia, São Paulo, v. 7, n. 2, p. 228-238, 2004 . 
MINAYO, M. C. S. O desafio do conhecimento: pesquisa qualitativa em saúde. 8. ed. São Paulo: Hucitec, 2004.

MORAES, S. A.; FREITAS, N. A. B.; MENDES, E. C. Protocolo fisioterápico para prevenção das complicações funcionais do paciente portador de fixador externo de Ilizarov em membro inferior. Reabilitar, São Paulo, v. 5, n. 18, p. 4-10, 2003.

OMS - ORGANIZACIÓN MUNDIAL DE LA SALUD. Lesiones por accidentes de tráfico en 1998. Ginebra, 2004. Disponível em: <http://www. transito.bvs.br>. Acesso em: 12 mar. 2006.

QUEIROZ, M. S.; OLIVEIRA, P. C. P. Acidentes de trânsito: uma visão qualitativa no município de Campinas, São Paulo, Brasil. Cadernos de Saúde Pública, Rio de Janeiro, v. 18, n. 5, p. 1179-1187, 2002.

QUEIROZ, M. S.; OLIVEIRA, P. C. P. Acidentes de trânsito: uma análise a partir das perspectivas das vítimas em Campinas. Psicologia e Sociedade, Porto Alegre, v. 15, n. 2, p. 101-123, 2003.

SAAD, I. A. B.; ZAMBON, L. Variáveis clínicas de risco pré-operatório. Revista da Associação Médica Brasileira, São Paulo, v. 47, n. 12, p. 117-124, 2001.

Recebido em: 13/08/2008

Reapresentado em: 29/08/2009

Aprovado em: 06/10/2009
SALTER, E.; STALLARD, P. Young people's experience of emergency medical services as road traffic accident victims: a pilot qualitative study. Journal of Child Health Care, London, v. 8, n. 4, p. 301-311, 2004.

SARTI, C. A. O atendimento de emergência a corpos feridos por atos violentos. Physis, Rio de Janeiro, v. 15, n. 1, p. 107-126, 2005.

SAUPE, R. et al. Competence of health professionals for interdisciplinary work. Interface: Comunicação, Saúde, Educação, São Paulo, v. 9, n. 18, p. 521-536, 2005.

SCHVARTSMAN, C.; CARRERA, R.; ABRAMOVICI, S. Avaliação e transporte da criança traumatizada. Jornal de Pediatria, Rio de Janeiro, v. 81, n. 5, p. S223-S229, 2005. Suplemento.

SÍCOLI, J. L.; NASCIMENTO, P. R. Health promotion: concepts, principles and practice. Interface: Comunicação, Saúde, Educação, São Paulo, v. 7, n. 12, p. 91-112, 2003.

TESSER, C. D. Medicalização social (I): o excessivo sucesso do epistemicídio moderno na saúde. Interface: Comunicação, Saúde, Educação, São Paulo, v. 10, n. 19, p. 61-76, 2006.

WHO - WORLD HEALTH ORGANIZATION. World report on road traffic injury prevention. Geneva, 2004. 